\title{
Concomitant injuries in patients with thoracic vertebral body fractures-a systematic literature review
}

\author{
Ulrich J. Spiegl ${ }^{1}$ - Georg Osterhoff ${ }^{1}$. Philipp Bula ${ }^{2} \cdot$ Frank Hartmann $^{3} \cdot$ Max J. Scheyerer ${ }^{4} \cdot$ Klaus J. Schnake $^{5}$. \\ Bernhard W. Ullrich ${ }^{6}$
}

Received: 3 December 2020 / Accepted: 8 February 2021 / Published online: 1 March 2021

(c) The Author(s) 2021

\begin{abstract}
Purpose The aim of this study was to give a systematic overview over the rate and location of concomitant injuries, the probability of suffering from neurological deficits, and to give evidence of the timing of surgery in severely injured patients with unstable thoracic vertebral body fractures.

Methods This review is based on articles retrieved by a systematic search in the PubMed and Web of Science database for publications up to November 2020 dealing with unstable fractures of the mid-thoracic spine.

Results Altogether, 1109 articles were retrieved from the literature search. A total of 1095 articles were excluded. Thus, 16 remaining original articles were included in this systematic review depicting the topics timing of surgery in polytraumatized patients, outcome neurologic deficits, and impact of concomitant injuries. The overall level of evidence of the vast majority of studies is low.

Conclusion The evidence of the available literature is low. The cited studies reveal that thoracic spinal fractures are associated with a high number of neurological deficits and concomitant injuries, particularly of the thoracic cage and the lung. Thereby, diagnostic algorithm should include computer tomography of the whole thoracic cage if there is any clinical sign of concomitant injuries. Patients with incomplete neurologic deficits benefit from early surgery consisting of decompression and long-segmental stabilization.
\end{abstract}

Keywords Thoracic spine fractures $\cdot$ Additional thoracic injuries $\cdot$ Neurologic deficit $\cdot$ Timing of surgical stabilization

Ulrich J. Spiegl

uli.spiegl@gmx.de

1 Department of Orthopaedics, Trauma Surgery and Plastic Surgery, University of Leipzig, Liebigstr. 20, 04103 Leipzig, Germany

2 Department of Orthopaedics and Trauma Surgery, Klinikum Gütersloh, Gütersloh, Germany

3 Center for Trauma and Orthopedic Surgery, Gemeinschaftsklinikum Mittelrhein, Ev. Stift, Koblenz, Germany

4 Department of Orthopedics and Trauma Surgery, University Hospital of Cologne, Cologne, Germany

5 Center for Spinal and Scoliosis Surgery, Malteser Waldkrankenhaus, St. Marien, Erlangen, Germany

6 Department of Trauma Surgery and Reconstructive Surgery, BG Klinikum Bergmannstrost, Halle, Germany

\section{Introduction}

The majority of articles dealing with thoracolumbar fractures are focusing on the thoracolumbar junction (TLJ) including the region between the 11th thoracic vertebral body and the 2nd lumbar vertebral body [21]. This is not surprising considering the distribution of vertebral fractures at the thoracolumbar spine. Reinhold et al. [14] included 865 patients with fractures of the thoracolumbar spine and reported $69 \%$ of the fractures at the thoracolumbar junction, whereas only $18 \%$ of the fractures were located between the 1 st and the 10th thoracic vertebral body (thoracic spine). This can be explained by the protective effect of the rib cage [20]. However, the rate of severe fractures with a high grade of instability defined by type B and C fractures is $71.5 \%$ at the thoracic spine. This rate substantially exceeds the rates of highly unstable fractures at the TLJ and the lumbar spine [14]. Thus, mainly high-energy trauma seems to be responsible for the majority of thoracic vertebral fractures in adult 
patients with healthy bone stock. However, this increases the risk of concomitant injuries such as the thoracic cage and the spinal cord [19]. This can have consequences on the diagnostic algorithm in order to avoid missing concomitant injuries and of the timing of the operative treatment in these patients.

Therefore, the aim of this study is to give a systematic overview of the rate and location of concomitant injuries, the probability of suffering from neurological deficits, and to give evidence of the timing of surgery in severely injured patients with unstable thoracic vertebral body fractures.

\section{Methods}

The literature search included unstable recent vertebral fractures ( $<4$ weeks) of the thoracic spine (Th 1-Th 10) of adults with adequate trauma history. Children and adolescents (age $<18$ ) and elderly (age > 65) with likely concomitant osteopenia/osteoporosis were not within the scope of this review and need to be analyzed separately. Furthermore, patients with fractures after non-adequate trauma (trivial falls from tripping) were not included in this review.

A systematic search of the literature was performed by two of the authors (UJS, BWU), including all articles until 05/11/2020. In each case, the two databases PubMed and Web of Science Core Collection were considered and searched. Excluded were articles dealing with osteoporotic or pathologic vertebral body fractures, cervical and/or lumbar vertebral body fractures, and exclusively non-operative therapy strategies. Additionally, case reports, reviews, and animals studies were excluded. Since data collection had already been completed at the time of PROSPERO registration, this review could not be registered with PROSPERO. Using the PICO scheme [3] the following review questions were defined:

- What concomitant injuries can be expected in patients with thoracic spine injuries?

- How many patients suffer from neurologic deficits caused by thoracic vertebral body fractures and what is the expected course of it?

- When to operate in polytraumatized patients?

The following search terms were used: "thoracic vertebral body fractures" OR "thoracic vertebral spine fractures" NOT "Osteoporosis" NOT "case report" NOT "tumor" NOT "lumbar spine".

Subsequently, all relevant original articles were analyzed based on their levels of evidence and their appropriate conclusions. Here, the following topic areas were defined:

- Neurologic deficits
- Impact of concomitant injuries

- Timing of surgery in polytraumatized patients

\section{Results}

Altogether, 1109 abstracts were retrieved from the literature search (Fig. 1). Of these, articles were excluded based on abstract or title. Most of the excluded studies were overlaps between both databases, animals studies, no original articles or were articles investigated other pathologies or included cervical or lumbar factures, or exclusively evaluated nonoperative treatment or anterior approaches. Altogether, 78 articles were analyzed completely. Of these articles 26 were additionally excluded, not focusing specifically on the thoracic spine, including geriatric patients or insufficiently describing the method of posterior stabilization. A total of 36 articles analyzed the technique of pedicle screw placement, the biomechanics of posterior stabilization of midthoracic fractures as well as the outcome of patients suffering from midthoracic fractures, and were excluded. Altogether, 1096 articles were excluded (Fig. 1). All 15 remaining original articles, which covered the period from 1971 to 2020 are summarized in Tables 1, 2, 3 and 4. Levels of evidence were defined as described by Bassler and Antes [1].

\section{Impact of additional thoracic injuries}

Six studies analyzed the percentage of additional thoracic injuries in combination with thoracic spine fractures (Table 1). In this context, an important but frequently overlooked combination is that of thoracic spinal injury and rib fractures. Those are commonly associated with pulmonary contusions, pneumothorax, and lung injury which may significantly contribute to the pulmonary morbidity and adverse impact on the patients` outcome [9]. Wang et al. [22] reported an incidence of $7.2 \%$ of rib fractures associated with traumatic spinal fractures. With a focus on thoracic spinal involvement the incidence increased up to $13.1 \%$ and in cases with unstable thoracic vertebral fractures up to $30 \%$ [9, 22]. Besides, the combination of thoracic spinal injury and rib fracture is a significant predictor for other more serious injuries and adverse events, like pulmonary complications, neurological deficits, other bone fractures, craniocerebral injuries, and death [9]. However, even more important is the combination of vertebral fractures and concomitant fractures of the sternum with an incidence of about $30 \%$ after thoracic spine fractures [8]. In most cases mechanism of injury is a high-energy deceleration trauma caused mainly by road traffic accidents and falls $[5,16]$. Morgenstern et al. [12] demonstrated that concomitant fractures of the sternum are an indicator for unstable injuries of the spine, particularly when the sternum fracture is located in the same segment of 


\section{Flow Chart of the Systematic Literature Review}

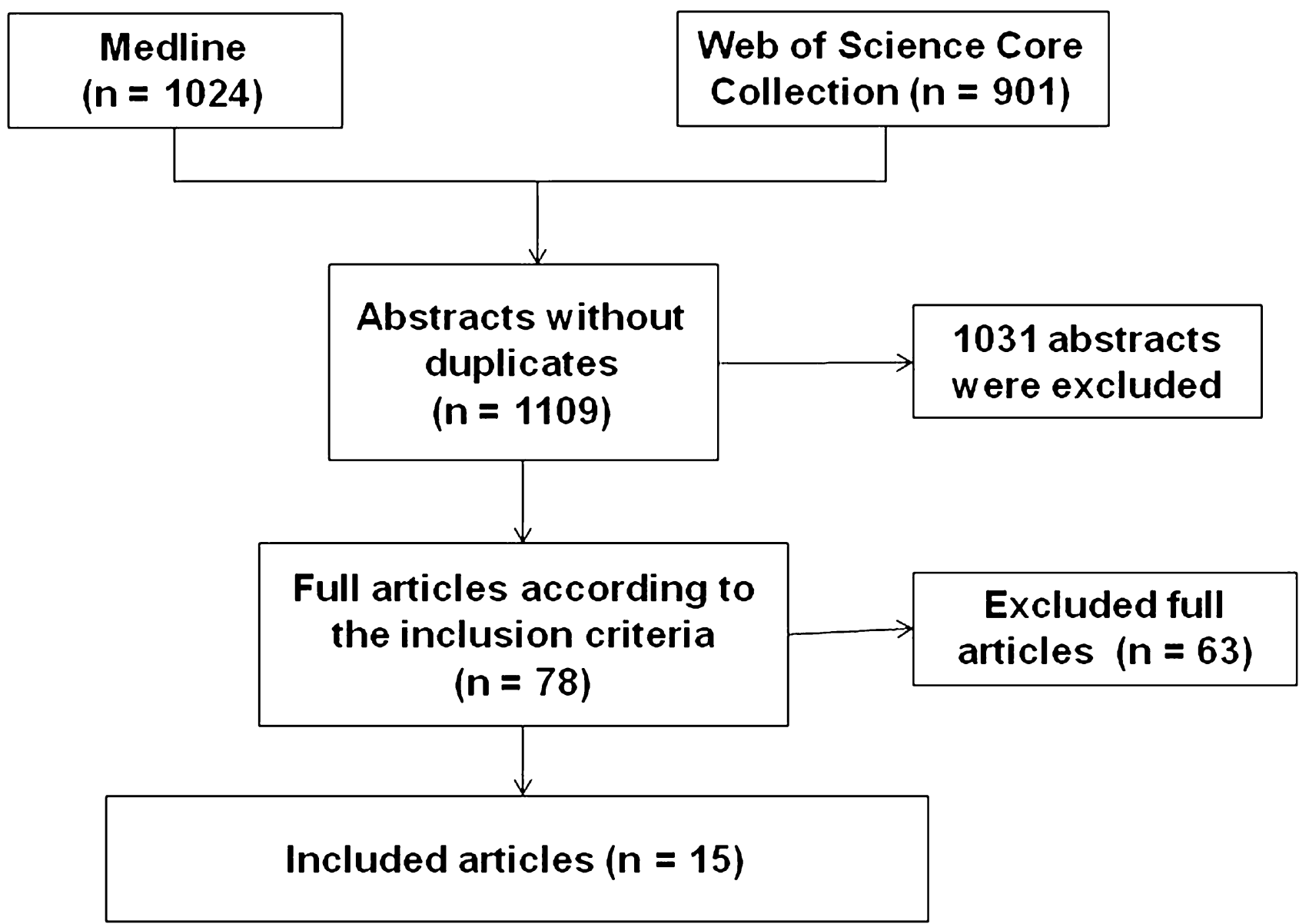

Fig. 1 Flowchart of the systematic literature review

the vertebral spine defect. Thus, rotational instability has to be expected. In contrast, displacement of the sternal fracture seems to have no influence on the severity of the thoracic spinal injury.

Additionally, in combination with unstable vertebral thoracic fractures, lung contusions are common and could be observed in 30-64\% of cases followed by other lung pathologies such as pneumo- or hematopneumothorax (24-46\%), pleural effusions (39\%), and lacerations of the lung (6\%) [5, 9]. Lesions of the lung go along with high mortality rates also due to secondary damage by posttraumatic inflammation. Besides, thoracic concomitant injuries associated with thoracic vertebral fractures are dissections or ruptures of the aorta, of the supra-aortal vessels, and of the vena cava superior [9].

\section{Concomitant non-thoracic injuries}

The relative numbers of associated concomitant pathologies are shown in Table 2. In addition to the concomitant thoracic injuries, several further non-thoracic pathologies were frequently seen in patients with thoracic vertebral body fractures. Thereby, injuries of the extremities were particularly often observed (19\% of the patients) [22]. Next, the rate of craniocerebral injuries rate of patients with thoracic vertebral fractures was $10.6 \%$ [22]. Additionally, mediastinal and abdominal visceral injuries were frequently seen (Table 2). 


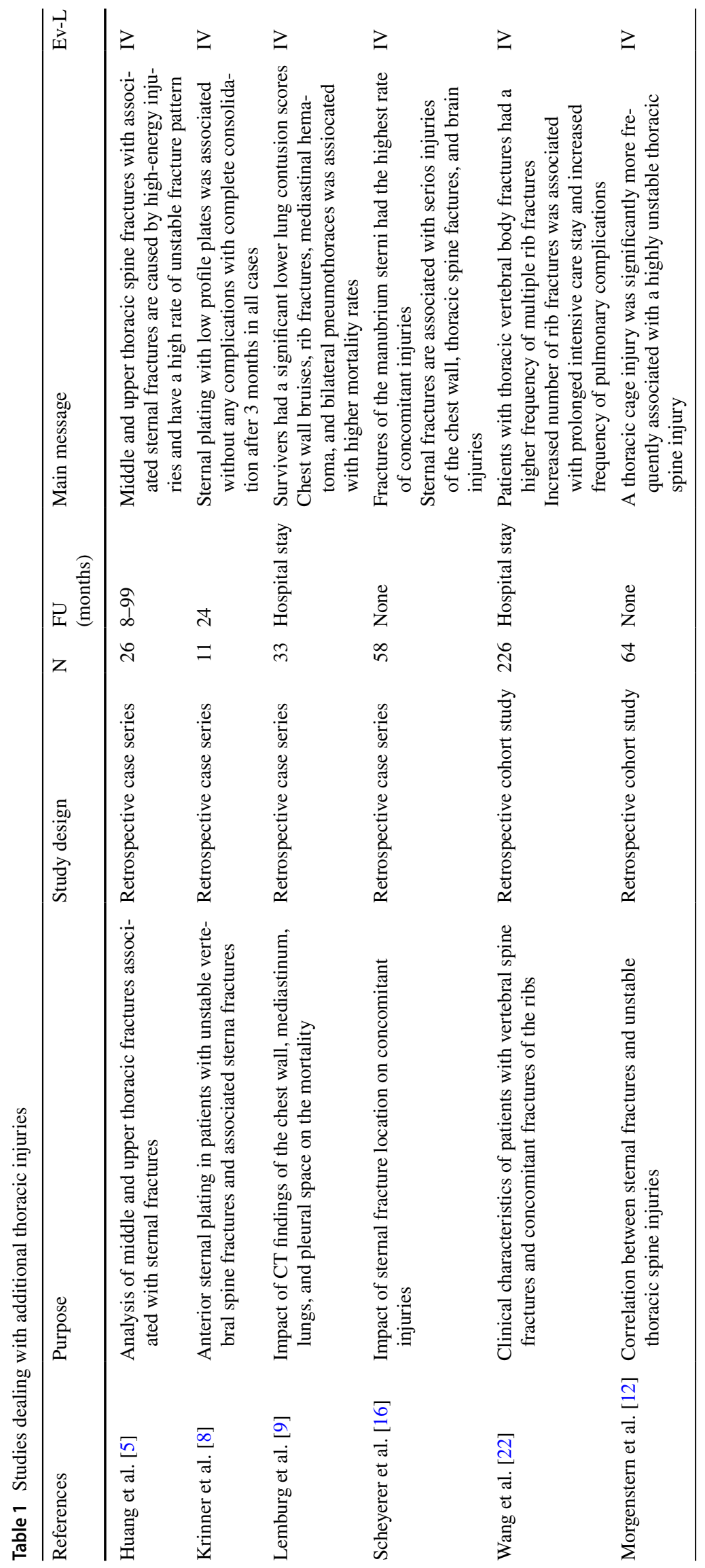


Table 2 The percentage and number of additional concomitant injuries are summed

\begin{tabular}{|c|c|c|c|c|c|c|c|}
\hline Article & $\begin{array}{l}\text { Rib fract } \\
\%(n)\end{array}$ & $\begin{array}{l}\text { Sternal fract } \\
\%(n)\end{array}$ & $\begin{array}{l}\text { Lung cont } \\
\%(n)\end{array}$ & $\begin{array}{l}\text { Pneumo-/Hemato- } \\
\text { thorax \% }(n)\end{array}$ & $\begin{array}{l}\text { Aortic } \\
\text { lesion \% }(n)\end{array}$ & $\begin{array}{l}\text { Cranio-cerebral } \\
\text { injuries \% }(n)\end{array}$ & $\begin{array}{l}\text { Abd. visceral } \\
\text { injuries \% (n) }\end{array}$ \\
\hline Wang et al. [22] & $22(226)$ & $2(5)$ & $28(64)$ & $11(24)$ & 0 & $11(24)$ & $4(8)$ \\
\hline Morgenstern et al. [12] & $64(41)$ & $10(206)$ & $64(41)$ & $42(54)$ & $2(1)$ & & \\
\hline Lemburg et al. [9] & $30(10)$ & $9(3)$ & $64(21)$ & $24(8)$ & 0 & & \\
\hline Huang et al. [5] & $100(26)$ & & $31(8)$ & $46(12)$ & & & $8(2)$ \\
\hline
\end{tabular}

Fract. Fracture, cont. contusion, abd. abdominal

Table 3 Articles dealing neurologic deficits

\begin{tabular}{|c|c|c|c|c|c|c|}
\hline References & Purpose & Study design & $n$ & $\begin{array}{l}\text { FU } \\
\text { (months) }\end{array}$ & Main Message & Ev-L \\
\hline Krengel et al. [7] & $\begin{array}{l}\text { Prognosis of patients with incom- } \\
\text { plete neurologic deficit and early } \\
\text { stabilization with decompression }\end{array}$ & Retrospective case series & 14 & 20 & $\begin{array}{l}\text { Average neurologic improvement } \\
\text { was } 2.2 \text { Frankel grades } \\
64 \% \text { had no deficits and final } \\
\text { follow-up }\end{array}$ & IV \\
\hline Place et al. [13] & $\begin{array}{l}\text { Comparison of operative with non- } \\
\text { operative treatment of patients } \\
\text { with complete paraplegia }\end{array}$ & Retrospective case series & 113 & $>60$ & $\begin{array}{l}\text { Longer inpatient stay in rehabilita- } \\
\text { tion of patients treated non-oper- } \\
\text { atively }\end{array}$ & IV \\
\hline Sapkas et al. [15] & $\begin{array}{l}\text { Outcome after stabilization and } \\
\text { decompression within } 4 \text { days after } \\
\text { trauma }\end{array}$ & Retrospective case series & 29 & $12-180$ & $\begin{array}{l}\text { All patients with Frankel A status } \\
\text { preoperatively remained their } \\
\text { status } \\
\text { All others improved by average of } \\
1.5 \text { Frankel scores }\end{array}$ & IV \\
\hline Sobottke et al. [18] & $\begin{array}{l}\text { Outcome after long-segmental } \\
\text { posterior stabilization with } \\
\text { decompression }\end{array}$ & Retrospective case series & 60 & $2-19$ & $\begin{array}{l}\text { Reduction loss was } 4.7^{\circ} \text { after } \\
\text { posterior only long-segmental } \\
\text { stabilization } \\
\text { No anterior might be necessary }\end{array}$ & IV \\
\hline
\end{tabular}

\section{Neurologic deficits}

Four studies included specifically patients with complete and incomplete neurologic deficits after suffering thoracic fractures (Table 3). Generally, unstable thoracic fractures carry a high risk of neurological deficit especially in type B and C injuries according to AO Spine classification. Although not included in this review due to the unselected inclusion of all thoracolumbar fractures, a German multicenter study is worth mentioning based on the high number of patients included (637 patients). A total of $117(18.4 \%)$ patients had thoracic injuries with 37 $(32.5 \%)$ patients suffering from a neurological deficit. On admission, 22 (18.8\%) patients were Frankel A, 4 (3.4\%) Frankel B, 4 (3.4\%) Frankel C, and 7 (5.9\%) Frankel D, respectively [14].

The other studies reported in their selected patient populations complete neurological deficits (Frankel A) between 76 and $83 \%[15,18]$. While patients with incomplete neurological deficits often recover over time, patients with complete deficits in the vast majority of cases remain paraplegic $[6,15]$. However, patients with complete neurology benefit from surgery by shorter inpatient stay in rehabilitation [13].
Early surgical intervention within $24 \mathrm{~h}$ including reduction, stabilization and decompression has been described in several studies $[7,15]$. The reported average neurological improvement in incomplete patients was either 1.5 or 2.2 Frankel grades on average per patient. However, patients with Frankel A either remained paraplegic or had little chance of improvement [15].

\section{Timing of surgical stabilization in severely patients}

Four studies analyzed the effect of early versus later surgery on the outcome in severely injured patients with thoracic vertebral body fractures (Table 4). Thereby, Schinkel et al. [17] analyzed the German National Trauma Database $(n=8057)$ and compared clinical parameters and outcomes of patients with severe thoracic spine injuries (Abbreviated Injury Scale $>2 ; n=298$ ) who underwent spine stabilization within $72 \mathrm{~h}$ after trauma or later. Ninety-five percent of all patients had additional severe thoracic injuries such as lung contusion. In spite of comparable demographic data, patients who underwent early surgical stabilization had a significant shorter intensive care unit stay, shorter mechanical ventilation, and shorter hospital stay. Expected mortality 


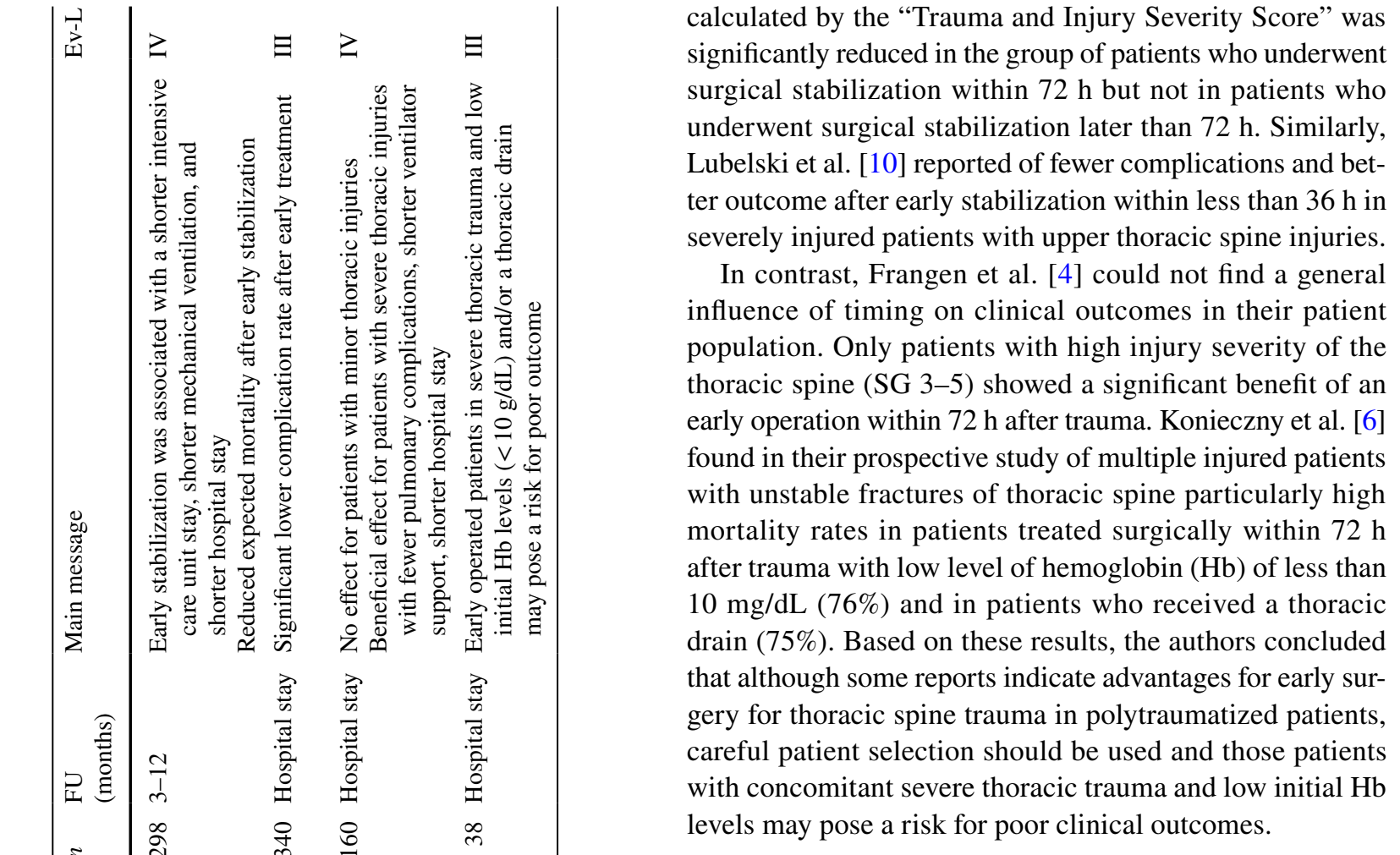

\section{Discussion}

The majority of articles that were selected had a low level of evidence (level IV). Therefore, a narrative presentation of the results was chosen.

Based on this, the most important findings of this study are the high association of concomitant neurologic deficits and concomitant pathologies to thoracic vertebral body fractures. Both have a tremendous impact on the patient and the further treatment. Particularly, neurologic deficits are a major impairment for the patients. The rate of complete paraplegias type Frankel A was very high ranging between 19 and $83 \%$ of the patients with low chances of improvement in the further course. In contrast, those patients with incomplete neurologic deficits had good chances to benefit from early surgical intervention. Early surgery consisted of decompression and long-segmental posterior stabilization during the $24 \mathrm{~h}$ after accident. The average improvement of 1.5-2.2 grades, that has been reported [7, 15], can make a huge difference for the patient implying that the patient is able to walk with or without medical aids, or being dependent on a wheelchair.

Concomitant injuries to the thoracic rib cage were reported in $7-30 \%$ of the patients with thoracic vertebral fractures. Under consideration that an intact rib cage provides $40 \%$ of the stability of the thoracic spine in flexion extension, $35 \%$ in lateral bending and $31 \%$ in axial rotation this can have tremendous impact of the thoracic spine 
stability [23]. Sternal fractures seem to have the highest impact on stability. Watkin et al. [23] found in a biomechanical study that a sternal fracture decreases the stability of the thoracic spine significantly by more than $42 \%$ in flexion extension. This was observed clinically, leading to the postulation that the sternal-rib complex is the fourth column of the spine [2]. Several authors recommend long-segmental posterior stabilization in thoracic vertebral fractures with concomitant thoracic cage fractures [19]. Additionally, operative stabilization of concomitant sternal fractures has been discussed. The authors recommend long-segmental posterior stabilization in patients with unstable thoracic vertebral body fractures and concomitant sternal fractures. Additionally, additional plate osteosynthesis of the sternum has to be discussed critically in patients with communicated fractures of the vertebral body and high load share scores (type McCormack [11] $\geq 6$ ) in order to minimize the chances of developing kyphotic malalignment.

Generally, due to the high rate of concomitant injuries in case of thoracic spinal fractures further diagnostic workup is imperative to optimize clinical outcome and to avoid overseeing serious and possible life-threatening lesions $[5,12$, 22]. The majority of studies dealing with concomitant injuries have focused on thoracic concomitant injuries $[5,12$, 22]. However, Wang et al. [22] observed a high rate of long bone fractures and craniocerebral injuries in these patients. This goes along with the high rate of high-energy accidents causing unstable thoracic spine fractures [14].

Unfortunately, the evidence level of the clinical follow-up studies is low. The timing of surgery, particularly in polytraumatized patients remains unclear [10, 17]. The majority of patients might benefit from early stabilizations within 36-72 h, whereas those patients with low hemoglobin levels as well as serious associated thoracic pathologies might benefit from surgeries at a later time point [6].

This study has several limitations. First of all articles might have been missed by the used search items and selectively including articles dealing with the thoracic spine only. Besides, the level of evidence in the majority of studies is low, leading to a limited conclusions that can be drawn out of it. Last but not least, the high number of studies with low evidence level was the reason to present the results in a narrative manner without any statistical evaluation of the strength of evidence and the precision of outcome parameters.

\section{Conclusions}

The evidence of the available literature is low. The cited studies reveal that thoracic spinal fractures are associated with a high number of neurological deficits and concomitant thoracic injuries. A diagnostic algorithm should include a computed tomography scan of the whole thoracic cage if there is any clinical sign of concomitant injuries. Patients with incomplete neurologic deficit benefit from early surgical decompression and long-segmental stabilization.

Funding Open Access funding enabled and organized by Projekt DEAL.

\section{Compliance with ethical standards}

Conflict of interest The authors declare that they have no conflict of interest.

Ethical approval This article does not contain any studies with human participants or animals performed by any of the authors.

Informed consent Not applicable.

Open Access This article is licensed under a Creative Commons Attribution 4.0 International License, which permits use, sharing, adaptation, distribution and reproduction in any medium or format, as long as you give appropriate credit to the original author(s) and the source, provide a link to the Creative Commons licence, and indicate if changes were made. The images or other third party material in this article are included in the article's Creative Commons licence, unless indicated otherwise in a credit line to the material. If material is not included in the article's Creative Commons licence and your intended use is not permitted by statutory regulation or exceeds the permitted use, you will need to obtain permission directly from the copyright holder. To view a copy of this licence, visit http://creativecommons.org/licenses/by/4.0/.

\section{References}

1. Bassler D, Antes G (2000) Wie erhalte ich Antworten auf meine Fragen? Lehrbuch Evidenzbasierte Medizin in Klinik und Praxis. Deutscher Ärzte-Verlag, Köln

2. Berg EE (1993) The sternal-rib complex. A possible fourth column in thoracic spine fractures. Spine 18(13):1916-1919

3. Farrugia P, Petrisor BA, Farrokhyar F, Bhandari M (2010) Practical tips for surgical research: research questions, hypotheses and objectives. Can J Surg J Canadien de Chirurgie 53(4):278-281

4. Frangen TM, Ruppert S, Muhr G, Schinkel C (2010) The beneficial effects of early stabilization of thoracic spine fractures depend on trauma severity. J Trauma 68(5):1208-1212. https:// doi.org/10.1097/TA.0b013e3181a0e558

5. Huang Z, Chen F, Huang J, Jian G, Gong H, Xu T, Wang B, Chen R, Chen X, Ye Z, Wang J, Xie D, Liu H (2015) Treatment of middle-super thoracic fractures associated with the sternum fracture. Int J ClinExp Med 8(6):9751-9757

6. Konieczny MR, Struwer J, Jettkant B, Schinkel C, Kalicke T, Muhr G, Frangen TM (2015) Early versus late surgery of thoracic spine fractures in multiple injured patients: is early stabilization always recommendable? Spine J 15(8):1713-1718. https://doi. org/10.1016/j.spinee.2013.07.469

7. Krengel WF 3rd, Anderson PA, Henley MB (1993) Early stabilization and decompression for incomplete paraplegia due to a thoracic-level spinal cord injury. Spine 18(14):2080-2087

8. Krinner S, Grupp S, Oppel P, Langenbach A, Hennig FF, SchulzDrost S (2017) Do low profile implants provide reliable stability 
in fixing the sternal fractures as a "fourth vertebral column" in sternovertebral injuries? J Thorac Dis 9(4):1054-1064. https:// doi.org/10.21037/jtd.2017.03.37

9. Lemburg SP, Frangen TM, Knoop H, Nicolas V, Heyer CM (2011) Prognostic pulmonary and thoracic findings in patients with unstable injuries of the thoracic spine. Pneumologie 65(7):412-418. https://doi.org/10.1055/s-0030-1256218

10. Lubelski D, Tharin S, Como JJ, Steinmetz MP, Vallier H, Moore $\mathrm{T}$ (2017) Surgical timing for cervical and upper thoracic injuries in patients with polytrauma. J Neurosurg Spine 27(6):633-637. https://doi.org/10.3171/2017.4.SPINE16933

11 McCormack T, Karaikovic E, Gaines RW (1994) The load sharing classification of spine fractures. Spine (Phila Pa 1976) 19(15):1741-1744

12. Morgenstern M, von Ruden C, Callsen H, Friederichs J, Hungerer S, Buhren V, Woltmann A, Hierholzer C (2016) The unstable thoracic cage injury: the concomitant sternal fracture indicates a severe thoracic spine fracture. Injury 47(11):2465-2472. https:// doi.org/10.1016/j.injury.2016.08.026

13. Place HM, Donaldson DH, Brown CW, Stringer EA (1994) Stabilization of thoracic spine fractures resulting in complete paraplegia. A long-term retrospective analysis. Spine 19(15):1726-1730

14. Reinhold M, Knop C, Beisse R, Audige L, Kandziora F, Pizanis A, Pranzl R, Gercek E, Schultheiss M, Weckbach A, Buhren V, Blauth M (2009) Operative treatment of traumatic fractures of the thoracic and lumbar spinal column. Part I: epidemiology. Der Unfallchirurg 112(1):33-42. https://doi.org/10.1007/s0011 3-008-1524-7

15. Sapkas GS, Papagelopoulos PJ, Papadakis SA, Themistocleous GS, Stathakopoulos DP, Efstathiou P, Sapoutzi-Krepia D, Badekas A (2003) Thoracic spinal injuries: operative treatments and neurologic outcomes. Am J Orthop 32(2):85-88

16. Scheyerer MJ, Zimmermann SM, Bouaicha S, Simmen HP, Wanner GA, Werner CM (2013) Location of sternal fractures as a possible marker for associated injuries. Emerg Med Int 2013:407589. https://doi.org/10.1155/2013/407589

17 Schinkel C, Frangen TM, Kmetic A, Andress HJ, Muhr G, German Trauma $R$ (2006) Timing of thoracic spine stabilization in trauma patients: impact on clinical course and outcome. J Trauma
61(1):156-160. https://doi.org/10.1097/01.ta.0000222669.09582 .ec (Discussion 160)

18 Sobottke R, Frangen T, Lohmann U, Meindl R, Muhr G, Schinkel C (2007) The dorsal spondylodesis of rotationally unstable thoracic fractures. Is additional ventral stabilization necessary? Der Chirurg Zeitschrift fur alleGebiete der operativenMedizen 78(2):148-154. https://doi.org/10.1007/s00104-006-1274-4

19. Spiegl UJA, Schnake KJ, Hartmann F, Katscher S, Riehle M, Scheyerer MJ, Schmeiser G, Siekmann H, Osterhoff G (2020) Traumatic fractures of the thoracic spine. Zeitschrift fur Orthopadie und Unfallchirurgie. https://doi.org/10.1055/a-1144-3846

20 Vaccaro AR, Rizzolo SJ, Allardyce TJ, Ramsey M, Salvo J, Balderston RA, Cotler JM (1995) Placement of pedicle screws in the thoracic spine. Part I: morphometric analysis of the thoracic vertebrae. J Bone JtSurg Am 77(8):1193-1199. https://doi. org/10.2106/00004623-199508000-00008

21. Verheyden AP, Spiegl UJ, Ekkerlein H, Gercek E, Hauck S, Josten C, Kandziora F, Katscher S, Kobbe P, Knop C, Lehmann W, Meffert RH, Muller CW, Partenheimer A, Schinkel C, Schleicher P, Scholz M, Ulrich C, Hoelzl A (2018) Treatment of fractures of the thoracolumbar spine: recommendations of the spine section of the German Society for Orthopaedics and Trauma (DGOU). Global Spine J 8(2 Suppl):34S-45S. https://doi.org/10.1177/2192568218 771668

22. Wang H, Zhou Y, Ou L, Li C, Liu J, Xiang L (2015) Traumatic vertebral fractures table 1 studies dealing with additional thoracic injuries and concomitant fractures of the rib in Southwest China, 2001 to 2010: an observational study. Medicine 94(44):e1985. https://doi.org/10.1097/MD.0000000000001985

23. Rt W, Watkins R 3rd, Williams L, Ahlbrand S, Garcia R, Karamanian A, Sharp L, Vo C, Hedman T (2005) Stability provided by the sternum and rib cage in the thoracic spine. Spine 30(11):1283-1286

Publisher's Note Springer Nature remains neutral with regard to jurisdictional claims in published maps and institutional affiliations. 